\title{
NEUROANATOMICAL STUDY OF INDIAN MAJOR CARP, CATLA CATLA (HAM.)
}

\author{
Yogesh. V. Bhute \\ Dada Ramchand Bakhru, Sindhu Mahavidyalaya, Panchpaoli Road, Nagpur-440 017 India. \\ Email:ybhute@yahoo.co.in
}

\begin{abstract}
:
Kluver and Barrera and Aldehyde fuchsin histochemical methods were used to study neuroanatomy of the olfactory organ, forebrain and pituitary gland in the major carp Catla catla. Organization of olfactory system in the C. catla, divided into sensory and nonsensory components. The sensory component consists of large number of olfactory receptor neurons (ORNs) that release axons forming over the olfactory nerve. The olfactory nerve fibers penetrate the bulb, spread along the periphery and possibly make synaptic contacts with the dendrites of the mitral cells. The olfactory bulb is divided into four layers, outer layer is olfactory nerve layer (ONL), below ONL, Glomerular layer (GL) is present. Olfactory bulb was connected to the forebrain by the medial olfactory tract (MOT) and the lateral olfactory tract (LOT). Forebrain was divided into telencephalon and diencephalon. In the telencephalon, larger size neurons forming a cluster adjacent to the lateral forebrain bundle (LFB) i.e. nucleus entopeduncularis (NE). Diencephalon was divided into preoptic area, hypothalamus, thalamus and epithalamus. In the Preoptic area, Nucleus preopticus (NPO) was divded in to Nucleus preopticus pars parvocellularis (NPOp) and pars magnocellularis (NPOm) were AFpositive. On the ventro-lateral side of the horizontal commissure (HC) in the preoptic area, nucleus of HC was localized. In the hypothalamus, behind the HC, tuberal area starts. In tuberal area, nucleus hypothalamicus (Nh), nucleus lateralis tuberis (NLT), nucleus recesses lateralis (NRL) and nucleus inferior lobi (NIL) prominently observed. Above hypothalamus, thalamus shows thalamic nuclei. Epithalamus show paired habenular ganglia over thalamus. Pituitary gland shows pars intermedia (PI), proximal pars distalis (PPD) and rostral pars distalis (RPD).
\end{abstract}

Key words: - Neuroanatomy, Olfactory organ, Forebrain, Pituitary gland.

\section{INTRODUCTION:}

Teleost represent the most abundant group of bony fishes covering about 28,400 species (Nelson, 2006). In fishes, olfaction is the most important sense, for the various kinds of behaviors such as feeding, homing, migration, reproduction and social interactions (Hara, 1967; Liley, 1982; Hara 1986; Doving, 1986; Satou, 1990). The olfactory bulb is the first relay station receiving primary olfactory nerve inputs, sending in its turn the output signals to several target areas in the telencephalon and diencephalon. In the fishes, teleost brain has comparable pattern as that of the other vertebrates but the exceptional feature is the absence of median eminence in teleost, so hypothalamic neurons directly innervating the pituitary cells. Therefore, teleostean hypothalomo-hypophysial system, offers a simple model to determine the anatomical relationship between the specific neurons. In teleost, forebrain was divided into telencephalon and diencephalon. Cytoarchitectonic pattern of the forebrain of teleost was studied in a several group of fishes (Ramakrishna and Subhedar, 1991; Arevalo et al., 1991; Riedel, 1997; Rodriguez-Gomez et al., 2000; Cerda-Reverter et al., 2001; Bhute et al., 2007; Baile et al., 2008). Stereotaxic atlas for the forebrain nuclei of the goldfish Carassius auratus (Peter and Gill, 1975) and the killifish: Fundulus heteroclitus (Peter et al., 1975) were also studied. Cytoarchitectonic pattern and the 
nomenclature of the nuclei were studied in some fishes (Meek and Nieuwenhuys, 1998).

Catla catla is an Indian major carp and economically important fish in India but there is no information available on its neuroanatomical structure. Present study plays an important role in understanding the structure of olfactory organ, forebrain and pituitary gland in Catla catla. This study will helpful in understanding correlation between various groups of neurons of olfactory organ, forebrain and pituitary gland in Catla catla. This information will also be useful in aquaculture, neuroscience and reproductive biology.

\section{MATERIAL \& METHODS:}

\section{Animal and tissue processing:}

Adult fish Catla catla $(\mathrm{n}=18)$ weighing $2 \mathrm{~kg}$ to $2.5 \mathrm{~kg}$ and ranging in length between 30 to $40 \mathrm{cms}$ were collected from the natural habitat. Fishes were brought to the laboratory and acclimatized in pond. Fishes were anaesthetized with $0.2 \%$ 2-phenoxy ethanol. Fishes were perfused transcardially with 750$850 \mathrm{ml}$ ice cold phosphate buffered saline (PBS, $\mathrm{pH}$ 7.45) followed by the same volume of icecold bouin's fixative. Olfactory organ with bulb and brain with pituitary gland were dissected out and post-fixed in the same fixative for 18 to $24 \mathrm{hrs}$. Olfactory organ with bulb and brain with pituitary gland were cut in transverse and sagittal planes at $10 \mu \mathrm{m}$ thickness. Alternate sections were stained with Nissl's stain (Kluver and Barrera, 1953) and Aldehyde fuschin (Gabe, 1953) to localize the neurosecretory material and differentiate between gray matter and white matter to identify the nuclei.

\section{Kluver and Barrera (1953) technique}

Sections of olfactory organ with bulb and brain with pituitary were deparaffinised in xylene and passed through serial grades of alcohol and brought them into 95\%alcohol.
Sections were stained in $0.1 \%$ solution of Luxol Fast Blue in 95\% alcohol for 6 to 8 hours at $57^{\circ} \mathrm{C}$. Sections were rinsed in $95 \%$ alcohol to wash off the excess stain and brought down to distilled water through descending grades of alcohol. Sections were differentiated quickly in $0.1 \%$ Lithium carbonate solution and passed through several changes of $70 \%$ alcohol till there will be a sharp contrast between the greenish blue white matter and colourless gray matter. Sections were washed thoroughly in distilled water and stained in $0.1 \%$ cresyl violet solution for 2 hours. Sections were differentiated in several changes of $95 \%$ alcohol, dehydrated, cleared in xylene and mounted in DPX and coverslipped.

\section{Aldehyde Fuschin (AF)}

Sections of brain and pituitary were deparaffinized in xylene and passed through descending grades of alcohol, brought to water and oxidized for 1 minute in $0.3 \%$ potassium permagnate solution acidified with sulphuric acid. Sections were decolourized quickly in $0.1 \%$ sodium metabisulphite. The sections were rinsed in distilled water, $70 \%$ alcohol and then stained with AF. Dehydrated in ascending grades of alcohol and mounted in DPX after clearing in xylene.

Brain atlas prepared for the olfactory organ and forebrain by plotting the sections from the series of transverse and sagittal sections. Each nuclear group in the olfactory organ and forebrain were explored using cytoarchitectonic criteria.

\section{Result}

In the Indian major carp Catla catla, paired olfactory organ are slightly lateral in position on snout. They are oval in shape.

\section{Olfactory system}

In the olfactory system, olfactory organ and olfactory bulb connected with short olfactory 
nerve. Olfactory organ has central raphae and lamellae on both the sides. In the adult fish olfactory organ is consist of 42 to 47 lamellae. Olfactory lamella shows sensory and nonsensory components in $C$. catla. The sensory component consists of large number of olfactory receptor neurons (ORNs) that release axons forming over the olfactory nerve. The olfactory nerve fibers penetrate the bulb, spread along the periphery and possibly make synaptic contacts with the dendrites of the mitral cells. The olfactory bulb is divided into four layers, outer layer is olfactory nerve layer (ONL), below ONL, Glomerular layer (GL) is present. The glomeruli innervate the multi-polar neurons called mitral cells which form the mitral cell layer (MCL). In the centre, densely packed small cells are present forming Granular cell layer (GCL). In the olfactory bulb near the olfactory tract bigger size cells are observed called as nervus terminalis (NT). Olfactory bulb is connected to the forebrain by the medial olfactory tract (MOT) and the lateral olfactory tract (LOT) (Fig. 1).

Olfactory receptor neurons are observed in the sensory region and goblet cells in the nonsensory region of the olfactory lamellae and the fiber fascicles are arising from the sensory region (Fig.4A). At the centre of the olfactory bulb in the GCL large number of granular cells showing intense Niss'l staining (Fig. 4B). In the MCL Larger size mitral cell showing intense Niss'l staining (Fig. 4C).

\section{Forebrain}

Forebrain of Catla catla is separated into telencephalon and diencephalon.

\section{Telencephalon}

Telencephalon in C. catla is made up of two hemispheres associated to each other by Anterior commissure (AC) and Commissure of Goldstein (GC). Each hemisphere is divided into two main regions i.e. area dorsalis telencephali and area ventralis telencephali. Area dorsalis telencephali is further divided into pars medialis (Dm), pars centralis (Dc), pars lateralis dorsal (Dld) and pars lateralis ventral (Dlv). Neurons in the medial region of dorsal telencephalon are small sized and rounded in shape is Dm. Dm shows moderate Niss'1 staining. The neurons in the area Dc shows intense Niss'l staining and neurons are thinly distributed. Neurons in the area Dld are sparsely distributed, rounded in shape and shows light Niss'l staining, while neurons in the area Dlv are spindle in shape, small in size densely distributed and moderately stained. Area ventralis telencephali is further divided into pars ventralis $(\mathrm{Vv})$, pars dorsalis $(\mathrm{Vd})$ and pars lateralis (Vl). Neurons in the $\mathrm{Vv}$ are small in size, sparsely distributed and show moderate Niss'l staining. Cells of the Vd are larger in size as contrast to $\mathrm{Vv}$, closely distributed and show intense Niss'l staining. In the area Vl, rounded shape, sparsely distributed and larger sized cells show moderate Niss'l staining. In the cerebral hemisphere, lateral forebrain bundles are present in vetro-lateral place. Nearby to the forebrain bundle, larger sized multi-polar neurons are observed. They are forming a cluster called as nucleus entopeduncularis (NE) (Fig.4D). NE shows intense Niss'l staining (Fig.4D). NE neurons are AF negative. Hemispheres of telencephalon are coupled with each other by Anterior commissure (AC) and Commissure of Goldstein (CG) situated dorsal to the preoptic recess (Fig. 2, 3).

\section{Diencephalon}

In Catla catla, diencephalon includes four areas preoptic area, hypothalamus, thalamus and epithalamus.

In the anterio-ventral diencephalon Preoptic area is an important region. It covers Preoptic recess of third ventricle and prosencephalic wall. Preoptic area is covered dorso-anteriorly 
by Anterior commissure, commissure of Goldstein, telencephalon and ventrally by the optic chiasma. In the preoptic area, neurons of Nucleus preopticus (NPO) are AF positive and other neuronal groups in the preoptic area are AF negative.

Aneurons of Nucleus of anterior commissure (NAC) is AF-negative. NAC is located below anterior commissure and above commissure of Goldstein on lateral side. Cells of NAC are thinly distributed, spindle shaped and show moderate Niss'l staining. Neuronal groups in the preoptic area are opposite in paraventricular region which is $\mathrm{AF}$ negative. In the preoptic area, Nucleus preopticus periventricularis (NPP) is also AF negative. NPP is located near the preoptic recess. NPP is subdivided into nucleus preopticus periventricularis dorsalis (NPPd) and ventralis (NPPv) (Fig.2, 3). Neurons of NPPv are in size small, densely distributed and show intense Niss'l staining. Neurons of NPPd are comparatively bigger size, and show moderate Niss'l staining. On the dorso-lateral side of optic chiasma supra chiasmatic nucleus ( $\mathrm{SCN})$ is located (Fig.2, 3). In SCN, neurons are small size, spindle shape and shows moderate Niss'l staining.

Nucleus of sub-ventricular gray (NSG) is neurons situated ventral to the preoptic recess. In NSG, neurons are oval in shape and showing moderate Nissl's staining. On the ventral margin of the preoptic recess Oraganum vasculosum laminae terminalis (OVLT) is located (Fig. 2, 3). In OVLT, parenchymal cells are seen and show intense Nissl's staining.

In Catla catla, neurons of NPO are present on the lateral side of the preoptic recess and ventricle. NPO is divided into NPO pars parvocellularis (NPOp) and NPO pars magnocellularis (NPOm). Neurons of NPOp are located above the optic chiasma and both the side of ventricle. NPOp neurons are larger in numbers and small in size. NPOm neurons are larger in size and less in numbers. NPOm neurons are located dorsally around the third ventricle (Fig.2, 3). Neurons of NPOp shows intense Niss'l staining (Fig.4E) and NPOm neurons also show intense Niss'l staining. Both NPOp and NPOm are AF positive and show accumulation of neuro-secretory material in the cytoplasm.

Horizontal commissure (HC) is localized below NPOm in the post optic area. It has paired nuclei i.e. Nucleus of horizontal commissure (NHC) that cover the horizontal commissure on ventro-lateral side (Fig.2, 3). The neurons are rounded in shape and show intense Niss'1 staining.

Hypothalamus is made up of tuberal area and inferior lobe. Tuberal area starts from posterior side of the Horizontal commissure. Tuberal area consists of neuronal groups located on either side of the third ventricle and lateral recess. In the tuberal area, prominently two neuronal groups i.e. nucleus hypothalamicus and nucleus lateralis tuberis are localized. It is present on the lateral side of the third ventricle shows three nuclei i.e. nucleus hypothalamicus ventralis (Nhv), nucleus hypothalamicus dorsalis (Nhd) and nucleus hypothalamicus medialis (Nhm) (Fig.2, 3). Nhv has small neurons and shows weak Niss'l staining. Dorsal side of the Nhv, round shaped neurons of Nhm shows weak Niss'l staining. Above Nhm, spindle or round shaped neurons of Nhd show moderate Niss'l staining. Nucleus lateralis tuberis (NLT) is nuclei of the tuberal area located near the infundibulum (Fig.2, 3). NLT is present ventral to the horizontal commissure and extended ventro-laterally and centrally in the hypothalamus. NLT is further classified on the basis of location and size of the neurons i.e. NLT pars lateralis (NLTl) and NLT pars medialis (NLTm). NLTl neurons are located laterally and large in size showing intense Niss'l staining 
(Fig.4G). NLTm neurons are localized near the third ventricle and comparatively smaller in size than NLT1 neurons. NLTm neurons are few in number and show moderate Niss'l staining.

On the posterior side of the tuberal area, lateral to the third ventricle lateral recesses is located. Compactly arranged neurons on the periphery of the lateral recesses are nucleus recesses lateralis (NRL) (Fig.2, 3). NRL is sub grouped into superior and inferior nuclei on the basis of their position i.e. nucleus recesses lateralis superior (NRLs), observed on the dorsal side of the lateral recess and nucleus recesses lateralis inferior (NRLi), localized on the ventral side of the lateral recess. NRLs composed of larger size of neurons and show moderate Niss'l staining. Neurons of NRLi are smaller in size and compactly arranged as compared to the NRLs neurons and show intense Niss'l staining.

Paraventricular organ (PVO) is located dorsally to the tuberal area and sited in the dorsal wall of the third ventricle. PVO is made up of loosely arranged columnar cells. They are of two types i.e. cells embedded within the ependyma called as intra-ependymal cells which are directly in the contact with the CSF and cells located slightly away from the ependyma called as subependymal cells that communicate with short processes. Both the types of cells are elongated and there are no morphological differences and paraventricular in position. It demarcates the dorsal margin of hypothalamus. The cells of PVO are in contact with CSF (Fig. 2, 3).

On the lateral side of the hypothalamus, nucleus of inferior lobi is located. On basis of position it has divided into two nuclei, nucleus inferior lobi pars dorsalis (NILd) and nucleus inferior lobi pars ventralis (NILv) (Fig.2, 3). NILd contain spindle shaped neurons and show moderate Niss'l staining. Neurons of the NILv are smaller in size, round shaped that show light Niss'l staining.
Thalamus in the $C$. catla divided into two regions on the basis of position of nuclear group's i.e. dorsal and ventral thalamus (Fig. 2, 3). In the dorsal thalamus, neurons of anterior thalamic nucleus (ATN) are rounded as well as spindle in shape, abundant in number and show moderate staining of Niss'1. Neurons in the posterior thalamic nucleus (PTN) are sparsely distributed, spindle or rounded in shape and show light Niss'l staining. In the ventral thalamus nuclear groups divided into ventro-medial thalamic nucleus (VMN) and ventro-lateral thalamic nucleus (VLN). The cells of the VMN are spindle shaped and show moderate Niss'l staining. The cells in the VLN are smaller in size, densely distributed and show light Niss'l staining.

Epithalamus is located dorsal to thalamus. It has a pair of habenular ganglion, i.e. two habenular ganglia are connected by a habenular commissure. Habenular ganglion has two nuclei i.e. dorsal habenular nucleus (DHN), and ventral habenular nucleus (VHN). In the DHN, cells are sparsely distributed show moderate Niss'l staining (Fig.2, 3, 4F).The neurons in the VHN are rounded and show moderate Niss'l staining (Fig.2, 3, 4F).

Pituitary of $C$. catla is attached to the hypothalamus by a short stalk and is forward in position. It is platybasic. The pituitary gland is subdivided into adenohypophysis and neurohypophysis. Adenohypophysis is further divided into rostral pars distalis (RPD), proximal pars distalis (PPD) and pars intermedia (PI) (Fig. 2, 3, 4H). In the PPD region larger cells shows the accumulation of secretary material are AF positive.

\section{RESULTS \& DISCUSSION:}

In C. catla, olfactory epithelium has central raphae from which radiating lamellae shows sensory and non-sensory regions. The nonsensory region is at the proximal end and basal 
region of the lamellae and sensory region at middle of the lamellae in C. catla. Location of these regions varies in different species. However, in the Osteoglossiformes $N$. notopterus the sensory region is at the proximal end and basal region of the lamellae (Baile et al., 2008), in Cyprinid L. rohita, sensory region is at the middle of the lamellae and nonsensory region is at the proximal and basal regions of lamellae (Bhute et al., 2007), in Rhodeus amarus, sensory region is at base and middle of the lamellae and nonsensory region is at the proximal end (Baby et al., 2000). In C. catla, olfactory bulb is of pedunculated type and connected to the telencephalon. Such type of olfactory organ is also found in other members of family Acanthidae, Cyprinidae and order Osteoglossiformes ( Bass, 1981; Bhute et al., 2007; Baile et al., 2008). Olfactory bulb has four layers from surface to the deep in C. catla. ORNs fibers extend caudally in the olfactory nerve and penetrate into the bulb from anterior side and spread along the periphery of the bulb in $C$. catla. ORNs fibers innervating and spreading in the bulb through the olfactory nerve were observed in some of the teleost (Ramakrishna and Subhedar, 1991; Baby et al., 2000; Bhute et al., 2007; Baile et al., 2008). In the olfactory bulb of $C$. catla near the olfactory tract, ventromedial and dorso-medial in position, ganglion cells are observed called as nervus terminalis (NT). Cluster of the deeply stained ganglion cells along ventromedial surface of the nervus terminalis is also reported in Ictalurus punctatus, L. rohit, and N. notopterus ( Bass, 1981; Bhute et al., 2007; Baile et al., 2008).

In $C$. catla two cerebral hemispheres connected to each other by anterior commissure (AC) and Commissure of Goldstein (GC) of telencephalon. It is divided into area dorsalis telencephali and area ventralis telencephali. Area dorsalis telencephali is subdivided into Dm, Dc, Dld, Dlv and area ventralis telencephali is subdivided into $\mathrm{Vv}, \mathrm{Vd}, \mathrm{Vl}$ and $\mathrm{NE}$. This type of pattern of nuclei in the telencephalon also observed in rayfinned teleost, Solea senegalensis, Dicentrarchus labrax, L. rohita and $N$. notopterus (Braford and Northcutt, 1983; RodriguezGomez et al., 2000; Cerda-Reverter et al., 2001; Bhute et al., 2007; Baile et al., 2008)

In Catla catla, diencephalon has four regions- preoptic area, hypothalamus, thalamus and epithalamus. Diencephalon is considered to be the most complex region in the brain of the teleost (Cerda-Reverter et al., 2001). In Carrassius auratus, Fundulus heteroclitus, Ictalurus punctatus, ray-finned fishes, Solea senegalensis, Dicentrachus labrax, L. rohita and $N$. notopterus epithalmus, thalamus, hypothalamus and preoptic area are included as the parts of the diencephalon (Peter and Gill, 1975 ; Peter et al., 1975; Bass, 1981; Braford and Northcutt, 1983; Rodriguez-Gomez et al., 2000; Cerda-Reverter et al., 2001; Bhute et al., 2007; Baile et al., 2008). In the goldfish, diencephalon is the neuronal integration centre for gustatory information, reproduction and vision (Braford and Northcutt, 1983).

Preoptic area, dorso-anteriorly roofed by Anterior commissure, commissure of Goldstein, telencephalon and ventrally by the optic chiasma in C.catla. In holosteans and teleost, preoptic area is the part of rostral-most diencephalic subdivision (Meek and Nieuwenhuys, 1998). In sunfish, perch, darter and goldfish, thin nucleus of sub-ventricular strand of gray which interconnects the nuclei of two sides (Crosby and Showers, 1969), in $N$. notopterus, NSG is unpaired group of cells at the preoptic recess (Baile et al., 2008) and in $C$. catla, NSG is situated ventral to the preoptic recess. NSG is also reported in reptile, Naja naja (Prasada Rao et al., 1981). The organum vasculosum laminae terminalis (OVLT) is considered as neurohaemal organ and highly vascularised. It is located on the ventral margin 
of the preoptic recess in C. catla. It is well developed in N. notopterus (Baile et al., 2008). OVLT has been reported in almost all the vertebrate classes (Tsuneki, 1986)

Neuronal groups in the preoptic area are paired in paraventricular region mostly AF negative except NPO in C. catla. In the preoptic area, Nucleus preopticus periventricularis (NPP) is also AF negative. NPP is located near the preoptic recess. NPP is subdivided into nucleus preopticus periventricularis dorsalis (NPPd) and ventralis (NPPv) in C. catla. In the Clarias batrachus and L. rohita also show the similar type of distribution of nuclei in the NPP (Ramakrishna and Subhedar, 1991; Bhute et al., 2007). The nucleus of anterior commissure (NAC) is associated with the anterior commissure in C. catla. NAC is also seen in reptiles and other teleost (Prasada Rao et al., 1981; Ramakrishna and Subhedar, 1991; Bhute et al., 2007; Baile et al., 2008). On the dorso-lateral side of optic chiasma supra chiasmatic nucleus (SCN) shows crowd of small cells in C. catla. $\mathrm{SCN}$ receives retinal projections are also reported in other teleost, amphibians, reptiles and mammals (Springer and Mednick, 1984; Neary and Northcutt, 1983; Prasada Rao and Subhedar, 1977; Arimura and Findley, 1971).

NPO of teleost is known to be homologous to the supra-optic and paraventricular nuclei of the higher vertebrates (Scharrer and Scharrer, 1954; Peter and Fryer, 1983; Fernald and Shelton, 1985). In Catla catla, neurons of NPOp and NPOm are situated above the optic chiasma and both the side of ventricle. NPOp and NPOm are $\mathrm{AF}$ positive in $C$. catla. $\mathrm{AF}$ positive small NPO cells referred as pars parvocellularis and large cells called as pars magnocellularis are observed in L. rohita (Bhute et al., 2007). AFnegative small NPO cells, referred as pars parvocellularis and AF-positive large cells called as pars magnocellularis are observed in some of the other teleost (Prasada Rao and Betole, 1973; Peter and Fryer, 1983; Baile et al., 2008 ) Hypothalamus has tuberal area and inferior lobe. Tuberal area starts from posterior side of the Horizontal commissure. Tuberal area consists of prominently two neuronal groups i.e. nucleus hypothalamicus (Nh) and nucleus lateralis tuberis (NLT) in C. catla. In C. catla NLT neurons are AF positive. NLT neurons are reported to be AF positive in some teleost (Belsare et al., 1970 ; Bhute et al., 2007). NLT is known be involved in the control of gonadotropic cells in number of teleost (Sathyanesan, 1970; Billard and Peter, 1977). In C. catla, on the paraventricular position of the third ventricle, the anterior tuberal area $\mathrm{Nh}$ consists of Nhm, Nhd and Nhv. The Nhm and Nhd are similar to that of nucleus periventricularis posterior of Corydora palitus and L. rohita (Millar 1940; Bhute et al., 2007. In other vertebrates' same area is described as a dorsal hypothalamic nucleus (Braford and Northcutt, 1983; Fernald and Shelton, 1985). In the caudal tuberal area, on the lateral side of the third ventricle is the lateral recesses. In the lateral recesses, compactly arranged neurons on the periphery are nucleus recesses lateralis (NRL) in the C. catla. In the tuberal area, NRL located in the similar position in the Clarias batrachus, L. rohita, and $N$. notopterus (Ramakrishna and Subhedar, 1991; Bhute et al., 2007; Baile et al., 2008). Paraventricular organ (PVO) is located dorsally to the tuberal area and sited in the dorsal wall of the third ventricle and cells of PVO are in contact with CSF in C. catla. Similar localization of PVO cells in the tuberal area also seen in the Clarias batrachus, L. rohita, and $N$. notopterus (Ramakrishna and Subhedar, 1991; Bhute et al., 2007; Baile et al., 2008).

In the hypothalamus, nucleus of inferior lobi has been divided into two nuclei on the basis of position, nucleus inferior lobi pars dorsalis (NILd) and nucleus inferior lobi pars ventralis 
(NILv) in the C. catla. In some teleost identical pattern is observed (Ramakrishna and Subhedar, 1991; Bhute et al., 2007; Baile et al., 2008). In Carrassius auratus, nucleus of inferior lobi is named as nucleus diffuse lobi inferioris and it is single nucleus (Peter and Gill, 1975).

Thalamus in the Haplochromis burtoni, Dicentrachus labrax and some rayfinned fishes, dorsal thalamus is divided in to three nuclei ATN, PTN and the central posterior thalamic nucleus (CPTN). Ventral thalamus is made up of nucleus of thalamic ementia (NTE), VLN, VLM and intermediate thalamic nucleus (ITN) (Braford and Northcutt, 1983; (Fernald and Shelton, 1985; Cerda-Reverter et al., 2001). In the $C$. catla dorsal thalamus divided into ATN and PTN and in the ventral thalamus, two nuclei are observed VLN and VMN such pattern also seen in $L$. rohita and $N$. notopterus (Bhute et al., 2007; Baile et al., 2008)

In some teleost habenular ganglion shows dorsal and ventral nuclei (Meek and Nieuwenhuys, 1998; Bhute et al., 2007; Baile et al., 2008) similar division of habenular ganglion is observed in C. catla.

In the $C$. catla., pituitary gland divided into adenohypophysis and neurohypophysis. Adenohypophysis is a cellular part which is sub divided into rostral pars distalis (RPD), proximal pars distalis (PPD) and pars intermedia (PI) Neurohypophysis is neuronal innervations from hypothalamus. In other teleost same pattern of division in the pituitary gland is observed (Ball and Baker, 1969; Peter et al., 1990).

Teleost is a important group in vertebrates as, they have direct innervation of hypothlamic nuclei in adenohypophysis. C. catla belongs to Indian major carps, that contributing major share in the fish production in India. But no work relate to neuroanotomical structure of brain and pituitary gland in detail. This will help in understanding the role of brain and pituitary gland in reproduction.

\section{REFERENCES:}

Arevalo, R., Alanso, J.R., Garcia-Ojeda, E., Brinon,. J.G., Crespo, C., and Aijon, J. (1995): NADPH-diaphorase in the central nervous system of the tench (Tinca tinca L., 1758). J. Comp. Neurol. 352, 398-420.

Arimura, A., and Findley, A. (1971). Hypothalamic map for the regulation of gonadotropin released based mainly on data obtained in the rat. Res. Reroduct. 3,1.

Baby, S.M., Ueck, M., and Prasada Rao, P.D. (2000.): Gonadotropin-releasing hormone-immunoreactive neurons and associated nicotinamide adenine nucleotide phosphate-diaphorasepositive neurons in the brain of teleost, Rhodeus amarus. Gen. Comp. Endocrinol. 120, 44-54.

Baile, V.V., Raut, I. N., and Bhute, Y.V.(2008): Organization Of Olfactory System, Forebrain And Pituitary Gland Of A Teleost, Notopterus notopterus. Annals Neurosci. 15, 43-50.

Ball, J.N., and Baker, B.I. (1969): The pituitary gland: Anatomy and histophysiology. In: Hoar WS, Randal DJ ED., Fish Physiology, Acad. Press New York. 2, 1-110.

Bass, A.H.(1981): Olfactory bulb efferents in the channel catfish, Ictalurus punctatus. J. Morph. 169, 91-111. 
Belsare, D.K., Belsare, S.G., and Murthy, P.S.R. (1970): Hypothalamohypophysial neurosecretory system in normal and hypophysectomised catfish, Clarias batrachus (Linn.). Acta. Zool. (Stock.) 51, 219-228.

Bhute, Y.V., Masram, S.C., Raut, I.N., and Baile, V.V. (2007): Cytoarchitectonic pattern of the olfactory system, forebrain and pituitary gland of the Indian major carp, Labeo rohita. Annals Neurosci. 14, 30-36.

Billard, R., and Peter, R.E.(1977): Gonadotropin release after implantation of anti-estrogen in the pituitary and hypothalamus of goldfish, Carassius auratus. Gen. Comp. Endocrinol. 32, 213-220.

Braford, R. M. Jr., and Northcutt, R.G.(1983): Organization of the diencephalon and pretectum of the rayfinned fishes. In: Davis $\mathrm{R}$, Northcutt R ED., Fish Neurobiology, University of Michigan Press, Ann. Arbor. 2, 361-368.

Cerda-Reverter, J.M., Zanui, S., and Munoz-Cueto, J. A. (2001): Cytoarchitectonic study of the brain of a perciformis species, the sea bass (Dicentrarchus labrax), II The diencephalon, J. Morphology 247, 229-251.

Crosby, E.C., and Showers, M.J. (1969): Comparative anatomy of the preoptic hypothalamic area. In: Haymaker W, Anderson E, Nauta, WJH (Eds.), The hypothalamus, Springfield III, Ch C Thomas. 61-135.

Doving, K.B. (1985): Functional properties of the fish olfactory system. In: D. Ottoson (Eds.). Progress in sensory physiology. Vol. 6. Springer Verlag, 39-104.

Fernald, R., and Shelton, .L. (1985): The organization of the diencephalon and the pretectum in the cichlid fish, Haplochromis burtoni. J. Comp. Neurol. 238, 202-217.

Gabe, M. (1953): Surquilquies applications de la coloration per le fuchsineparaldehyde. Bull. Micr. Appl. 3, 153-162.

Hara, T.J. (1967): Electrophysiological studies of the olfactory system of goldfish, Carassius auratus L. III. Effect of sex pheromone on the electrical activity of the olfactory bulb. Comp. Biochem. Physiol. 222, 209-226.

Hara, T.J. (1986): Role of olfaction in fish behavior. In: T.J. Pitcher (Eds.). Behaviors of teleost fishes. Croom Helm. London. 152-176.

Kluver, H., and Barrera, E. (1953): A method for the combined staining of cells and fibers in the neurons system. J. Neuropathalo. Exp. Neurol.12, 400-403.

Liley, N.R.(1982): Chemical communication in fish. Can. J. Fish Aquat. Sci. 139, 22-35. 
Meek, J., and Nieuwenhuys, R.(1998): Holosteans and teleost. In: Nieuwenhuys R, Ten Donkelaar HJ, Nicholson C ED., Central Nervous System of Vertebrates, 2, 759-937.

Millar, R.N. (1940): The diencephalic cell masses of the teleost, Corydora paliatus. J. Comp. Neurol. 73, 345378.

Neary, T.J, and Northcutt, R.G. (1983): Nuclear organization of bull frog diencephalon. J. Comp. Neurol. 23, 262-278.

Nelson, J.S. (2006): Fishes of the world. New York. John Wiley and Sons, Inc, VI, 601.

Peter, R.E., and Fryer, J.N. (1983): Endocrine functions of the hypothalamus of Actinopterygii. In: Davis R, Northcutt R ED., Fish Neurobiology, University of Michigan Press, Ann. Arbor. 2, 165-201.

Peter, R.E., and Gill, V.E. (1975): A stereotaxic atlas and technique for forebrain nuclei of the goldfish, Carrassius auratus. J. Comp. Neurol. 159, 69-102.

Peter, R.E., Macey, M.J., and Gill, V.E. (1975): A stereotaxic atlas and technique for forebrain nuclei of the killifish, Fundulus heteroclitus. J. Comp. Neurol. 159,103-128.

Peter, R.E., Yu, K.L., Marchant, T.A., and Rosenblum, P.M. (1990): Direct neural regulation of the teleost adenohypophysis. J. Exp. Zool. Suppl. 4, 84-89.

Prasada Rao, P.D., and Betole, U. K. (1973): Changes in the hypothalamohypophysial complex after gonadectomy in the catfish, Clarias batrachus (Linn.). Zool. Beitr. 19, 319-333.

Prasada Rao, P.D., Subhedar, N., and Raju, P.D. (1981): Cytoarchitectonic pattern of the hypothalamus in the cobra, Naja naja. Cell Tissue Res. 217, 503-529.

Prasada Rao, P.D., and Subhedar, N. (1977): Cytoarchetectonic study of the hypothalamus of the lizzard, Calotes versicolor. Cell Tissue Res. $180,63-85$.

Ramakrishna, N.S., and Subhedar, N. (1991): Cytoarchitectonic pattern of hypothlamus in the catfish, Clarias batrachus (Linn.). J. Hirn. Forsch. 32(3), 289-308.

Riedel, G. (1997): The forebrain of the blind cave fish Astynanax hubbs (Characidae). Brain Behav. Evol. 41(1), 20-38.

Rodriguez-Gomez, F.J., Rendon-Unceta, M.C., Sarasquete, C., and MunozCueto, J.A. (2000): Localization of tyrosine hydroxylaseimmunoreactivity in the brain of the Senegalese sole, Solea senegalensis. J. Chem. Neuroanat. 19, 17-32. 
Sathyanesan, A.G. (1970):The nucleus preopticus of the fresh water catfish, Clarias batrachus (L.) Zool. Beitr. 16, 247-255.

Satou, M. (1990): Synaptic organization, local neuronal circuitry, and functional segregation of the teleost olfactory bulb. Prog. Neurobiol. 34, 115-142.

Scharrer, E.A., and Scharrer, B. (1954): Hormones produced in neurosecretory cells. Recent progr. Hormone Res. 10, 183-240.
Springer, A.D., and Mednick, A.S. (1984): Selective innervations of the goldfish suprachiasmatic nucleus by ventral retinal ganglion cell axons. Brain Res. 323, 293-296.

Tsuneki K. (1986): A survey of occurrence of about seventeen circumventricular organs in brains of various vertebrates with special reference to lower groups. $J$ Hirnforsch. 27, 441-70.

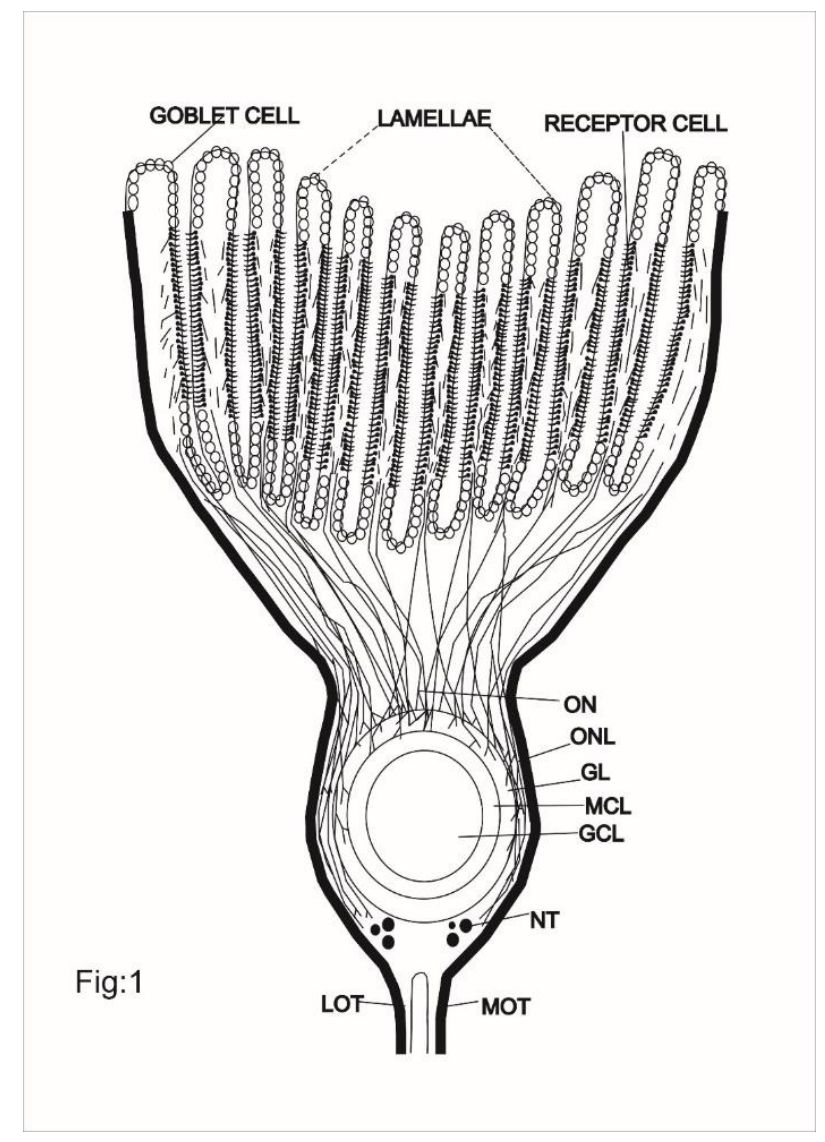

Fig. 1. Diagrammatic representation of the sagittal section of the olfactory system of Catla catla showing, GCL, granular cell layer; GL, glomerular layer; LOT, Lateral olfactory tract; MCL, mitral cell layer; MOT, medial olfactory tract; NT, nervous terminalis; ON, olfactory nerve; ONL, olfactory nerve layer. 


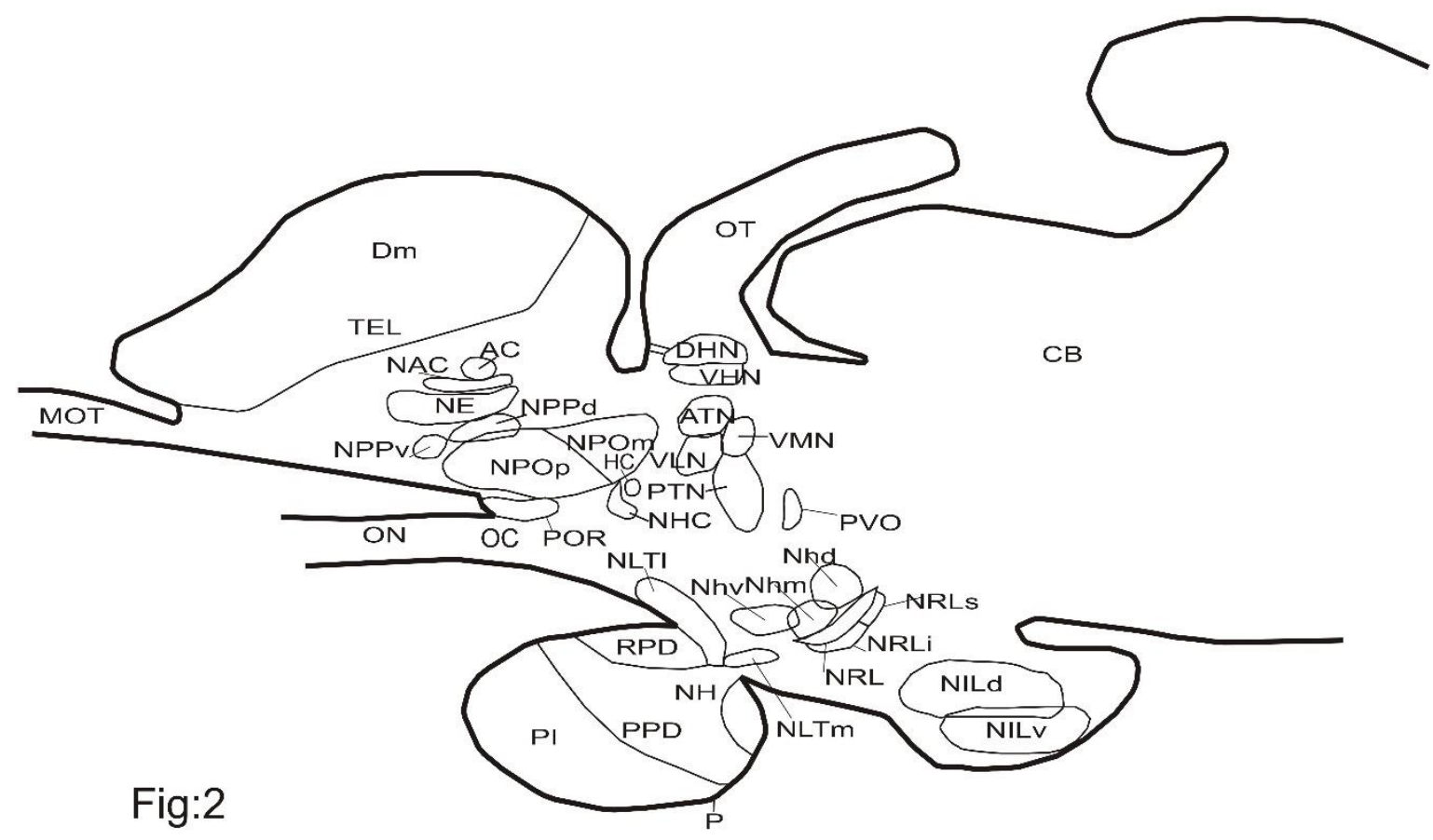

Fig. 2. Diagrammatic representation of the saggital section of forebrain and pituitary gland showing, AC, anterior commissure; ATN, anterior thalamic nucleus; $\mathrm{CB}$, cerebellum; $\mathrm{Dm}$, area dorsalis telencephali pars medialis; DHN, dorsal habenular nucleus; HC, Horizontal commissure; MOT, medial olfactory tract; NAC, nucleus anterior commissure; NE, Nucleus entopeduncularis; NH, Neurohypophysis; NHC, Nucleus horizontal commissure; Nhd, nucleus hypothalamicus dorsalis; Nhm, nucleus hypothalamicus medialis; Nhv, nucleus hypothalamicus ventralis; NILd, nucleus inferior lobi pars dorsalis; NILv, nucleus inferior lobi pars ventralis; NLTl, nucleus lateralis tuberis pars latralis; NLTm, nucleus lateralis tuberis pars medialis; NPOm, Nucleus preopticus pars magnocellularis; NPOp, nucleus preopticus pars parvocellularis; NPPd, nucleus preopticus periventricularis dorsal; NPPv, nucleus preopticus periventricularis ventral; NRL, nucleus recesses lateralis; NRLi, nucleus recesses lateralis inferior; NRLs, nucleus recesses lateralis superior; OC, optic chiasma; ON, optic nerve; OT, optic tectum; P, pituitary gland; PI, pars intermedia; POR, preoptic recesses; PPD, proximal pars distalis; PTN, posterior thalamic nucleus; PVO, paraventricular organ; RPD, rostral pars distalis; TEL, telencephalon VHN, ventral habenular nucleus; VLN, ventrolateral thalamic nucleus; VMN, ventromedial thalamic nucleus. 


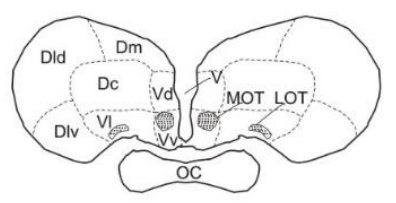

A

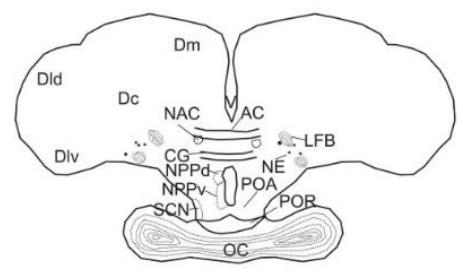

B

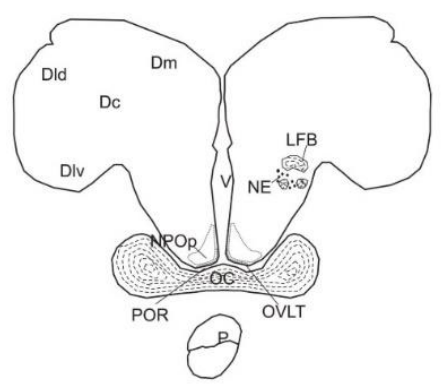

C

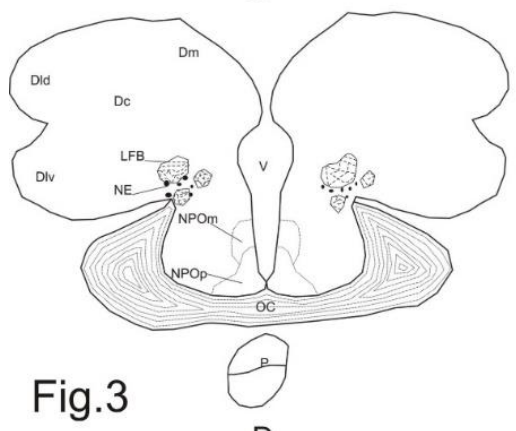

D

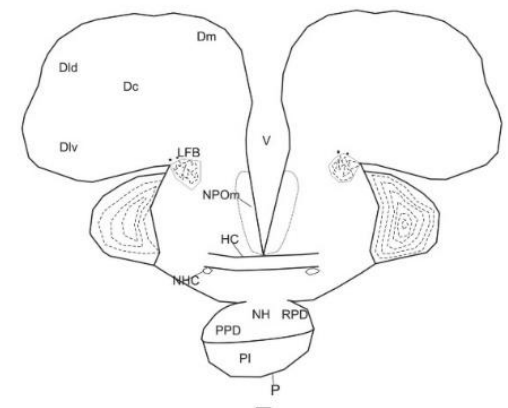

E

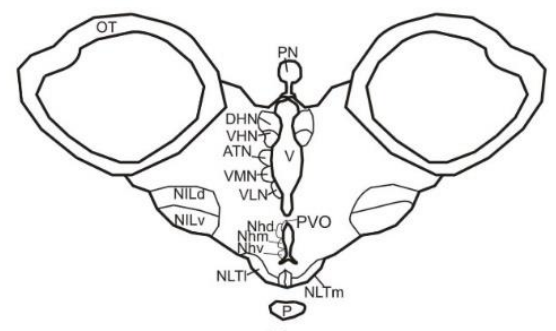

$\mathrm{F}$

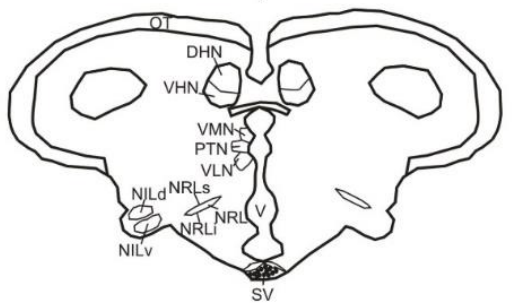

G

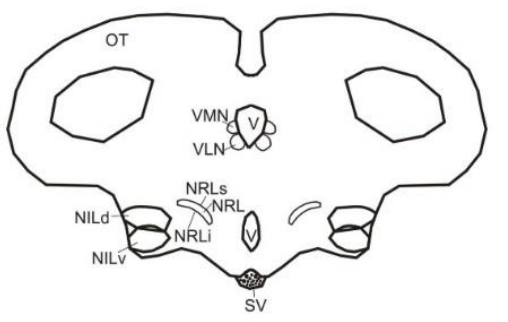

$\mathrm{H}$

Fig. 3. Diagrammatic representation of the transverse section of the forebrain of Catla catla showing, AC, anterior commissure; ATN, anterior thalamic nucleus; CG, commissure of Goldstein; Dc, area dorsalis telencephali pars centralis; DHN, dorsal habenular nucleus; Dld, area dorsalis telencephali pars lateralis dorsal; Dlv, pars lateralis ventral; Dm, pars medialis; HC, Horizontal commissure; LFB, Lateral forebrain bundle; LOT, Lateral olfactory tract; MOT, medial olfactory tract; NAC, nucleus anterior commissure; NE, Nucleus entopeduncularis; NH, Neurohypophysis; NHC, Nucleus horizontal commissure; Nhd, nucleus hypothalamicus dorsalis; Nhm, nucleus hypothalamicus medialis; Nhv, nucleus hypothalamicus ventralis; NILd, nucleus inferior lobi pars dorsalis; NILv, nucleus inferior lobi pars ventralis; NLTl, nucleus lateralis tuberis pars latralis; NLTm, nucleus lateralis tuberis pars medialis; NPOm, Nucleus preopticus pars magnocelularis; NPOp, nucleus preopticus pars parvocellularis; NPPd, nucleus preopticus periventricularis dorsal; NPPv, nucleus preopticus periventricularis ventral; NRL, nucleus recesses lateralis; NRLi, nucleus recesses lateralis inferior; NRLs, nucleus recesses lateralis superior; OC, optic chiasma; OT, optic tectum; OVLT, organum vasculosum laminae terminalis P, pituitary gland; PI, pars intermedia; POA, preoptic area; POR, preoptic recesses; PPD, proximal pars distalis; PTN, PVO, paraventricular organ;posterior thalamic nucleus; RPD, rostral pars distalis; SCN, suprachiasmatic nucleus; SV, succus vasculosus; Sy, V, ventricle; $\mathrm{Vd}$, area ventralis telencephali pars dorsalis; VHN, ventral habenular nucleus; Vl, area ventralis telencephali pars latralis; VLN, ventrolateral thalamic nucleus; VMN, ventromedial thalamic nucleus. Vv, area ventralis telencephali pars ventralis. 

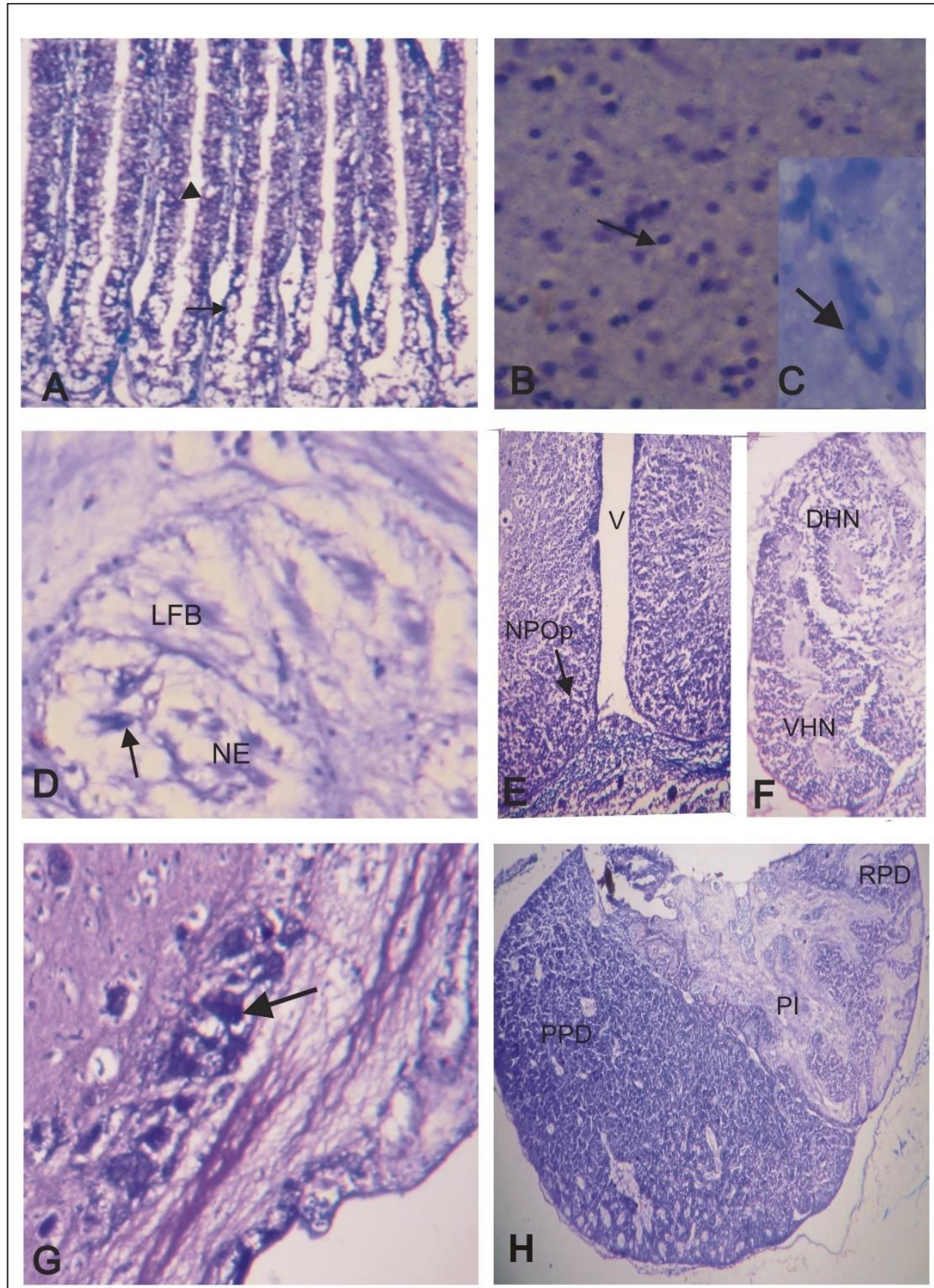

Fig :4

Fig.4. Sagittal and transverse sections of olfactory bulb and brain of Catla catla. A) Transverse section of the olfactory organ showing the olfactory receptor neuron in the sensory region (arrow head) and goblet cells in the non-sensory (arrow) regions of the olfactory lamellae. Kluver and Barrera 400X. B) Olfactory bulb showing granular cells with intense Niss'l staining (arrow) Kluver and Barrera 400X. C) In the Olfactory bulb Larger size mitral cell showing intense Niss'l staining (thick arrow). D) Telencephalon showing bigger size neurons adjacent to the lateral forebrain bundle (LFB) in nucleus entopenducularis (NE) with intense Niss'l staining (arrow) Kluver and Barrera 400X E) Diencephalon showing intense Niss'l staining in nucleus preopticus pars parvocellularis (NPOp) (arrow) adjacent to the $3^{\text {rd }}$ ventricle(V) Kluver and Barrera $160 \mathrm{X}$ and F) Epithalamus showing habenular ganglion with dorsal habenular nucleus (DHN) and ventral habenular nucleus (VHN). Kluver and Barrera 160X G) Tuberal area showing bigger sized neurons located laterally showing intense Niss'l staining in nucleus lateralis tuberis pars lateralis (NLTl) (arrow). Kluver and Barrera 160X. H) Sagittal section of pituitary gland showing rostral pars distalis (RPD), proximal pars distalis (PPD) and pars intermedia(PI). Kluver and Barrera 25X 